\title{
Heritability and Correlations for Biomass Production and Allocation in White Spruce Seedlings ${ }^{1)}$
}

\author{
By D. M. Rweyongeza ${ }^{2),}$, F. C. YeH ${ }^{3)}$ and N. K. DhiR ${ }^{4)}$
}

(Received 12 ${ }^{\text {th }}$ June 2005)

\begin{abstract}
Tree growth is a multidimensional trait and families vary for components of growth such as height, diameter, foliage and roots. Therefore, variation in tree growth is better studied by analysing biomass production and allocation than simple traits. In addition, biomass is better linked to products such as pulp and wood energy than simple traits. We analysed biomass of 3 -year old open-pollinated greenhouse seedlings of white spruce to determine (1) heritability for biomass production and allocation to shoot and root components, (2) correlations between biomass traits, and biomass traits with primary traits, and (3) correlation between biomass production in the greenhouse and height growth for the same families in the field. The study had a randomised complete block design with single-tree plots, 30 blocks and 58 open-pollinated families. Individual-tree heritability $\left(h_{i}^{2}\right)$ and family mean heritability $\left(h_{f}^{2}\right)$ ranged from 0.200 to 0.333 and 0.374 to 0.516 for green weight, respectively. Likewise, $h_{i}^{2}$ and $h_{i}^{2}$ ranged from 0.186 to 0.359 and 0.352 to 0.536 for dry weight, respectively. Genetic correlation $\left(r_{q}\right)$ between green and dry weight ranged from 0.943 to 1.015 , while $r_{a}$ between shoot and root dry weight ranged from 0.947 to 0.955 . In contrast, $r_{a}$ between biomass traits and field height ranged from -0.403 to -0.124 . Thus, we conclude (1) variation in biomass production and allocation exhibited low genetic basis, (2) testing and selection for green or dry weight should lead to similar genotypes, (3) biomass allocation may not be easily altered by selection and breeding, and (4) indirect early selection based on seedling biomass would be ineffective for improving field height.
\end{abstract}

Key words: Dry weight, early selection, genetic variation, heritability, Picea glauca.

\section{Introduction}

Genetic variation in tree growth often is assessed on height, diameter and volume production. The use of height more than other growth traits in tree breeding is due to ease of measurement (KREMER, 1992; ADAMS et al., 2001), and its high correlation with diameter (YANCHUK and KISS, 1993; Wu et al., 1995) and volume (HodGe and White, 1992), which is a common measure of wood production and marketing in forestry. The

1) Based in part on the Ph.D. thesis submitted to the University of Alberta by the first author.

2) Department of Agricultural, Food and Nutritional Science University of Alberta, Edmonton, AB, Canada, T6G 2P5.

$\left.{ }^{3}\right)$ Department of Renewable Resources, University of Alberta, Edmonton, AB. Canada, T6G 2H1.

4) Forest Management Branch, Alberta Sustainable Resource Development, Edmonton, AB, Canada T5K 2M4.

*) Corresponding author: Tel. 780-422-5436, Fax: 780-427-0084, Email: $\underline{\text { drweyong@ualberta.ca }}$ increasing emphasis for complete utilization of trees and use of wood as a source of energy makes it necessary for marketing of wood to be conducted by weight rather than volume (AverY and BURKHART, 1994). This is because dry weight is better correlated with the final products such as pulp than wood volume is (AvERY and BURKHART, 1994). When wood marketing by weight becomes routine, tree breeders will have to breed trees for biomass production rather than volume per area. There will also be a need for altering biomass allocation of selected genotypes to maximise allocation to harvestable tree parts.

Genetic studies of old trees have been conducted in conifers and indicate that biomass production and allocation has moderate heritability (ST. CLAIR, 1994a, 1994b). A majority of studies in the genetics of tree biomass has been conducted with tree seedlings predominantly in Pinus species and Norway spruce (Wu and YEH, 1997; SONESSON et al., 2002; SonESSON and ERIKSSON, 2000) and have generally revealed low heritability for biomass production. Field progeny trials serve as laboratories for assessing age trends in the genetic variation of many morphological and physiological traits. Therefore, these trials are rarely sacrificed for one-time destructive assessment of variation in biomass production and allocation. In addition, extraction and drying of large tree parts is tedious and time consuming, which may limit the use of old trees for biomass studies. Therefore, indoor and nursery seedlings are excellent genetic materials used to simulate growth variation in field trees.

Most of the reported studies on the genetics of tree biomass equate biomass production with biomass allocation. Like other organisms, plant parts grow proportionally to each other and to the overall size of the plant (see GAYON, 2000; Gould, 1971; Monserud and MARSHAL, 1999). Large plants have larger branch, trunk and root fresh and dry weight than small plants. Consequently, variation in absolute weight is a result of variation in plant size not variation in biomass allocation. To analyse variation in biomass allocation, the absolute partition weight could be adjusted for allometric relationships with the overall seedling biomass depending on the design of the experiment. Alternatively, analysis could be made on the ratio of partition weight to the overall seedling weight. In either case, the objective is to make variation in biomass allocation as independent of the overall seedling size as possible.

In this article, we present results from a retrospective greenhouse progeny test of white spruce (Picea glauca (Moench) Voss) in Alberta, Canada. The objectives were to (1) determine the heritability of biomass production 
and its allocation to shoot and root compartments, (2) estimate genetic, phenotypic and environmental correlations between biomass traits and primary seedling variables, and (3) determine the genetic correlation between biomass production in greenhouse seedlings and 10- and 11-year height of progenies from the same families at two field sites. We hypothesised that due to the allometric nature of plant growth, biomass allocation has lower heritability than biomass production and other growthrelated traits.

\section{Materials and Methods}

\section{Test Material and Experimental Procedures}

The 58 families involved in the greenhouse study were collected as open-pollinated seedlots from the Peace River region in northwestern Alberta, Canada. The sampled region is located at $54^{\circ} 31^{\prime}-58^{\circ} 03^{\prime} \mathrm{N}$, $117^{\circ} 35^{\prime}-119^{\circ} 22^{\prime} \mathrm{W}$, and $365-945$ metres above sea level. These families were earlier included in the progeny study at Chinchaga $\left(57^{\circ} 50^{\prime} \mathrm{N}, 118^{\circ} 12^{\prime} \mathrm{W}\right.$ and 470 metres above sea level) and Saddle Hills (55 $31^{\prime} \mathrm{N}$, $119^{\circ} 40^{\prime} \mathrm{W}$ and 914 metres above sea level). At both sites, the experimental design was a randomised complete block with 6 blocks and 6-tree row plots. Spacing between trees was $2.5 \times 2.5$ metres. These trials were measured for 10- and 11-year height from seeds.

Between 1996 and 2000, a greenhouse retrospective progeny test was conducted at the University of Alberta in Edmonton to estimate among other things, the correlation between greenhouse traits and field growth. The experimental layout was a randomised complete block design with single-tree plots and 30 blocks. The growth medium was a $2: 1$ (volume) peat moss to vermiculite mixture with $5.0 \mathrm{~g} \mathrm{~L}^{-1}$ of lime added to maintain the $\mathrm{pH}$ at about 5.0. Seed germination and seedling growth were conducted in the same $700 \mathrm{ml}$ styroblocks. Seedlings were raised at an extended photoperiod of approximately 20 hours per day from a combination of natural and artificial light. The temperature was set at $23^{\circ} \mathrm{C}$ day and night.

The experiment was carried out for three growing seasons of 18 weeks each from May to late August each year. At the end of the first and second growing seasons, seedlings were kept outside the greenhouse in protected sheds for over-wintering, which extended from September of the current year to April of the following year. Seedlings were watered once a day and fertilised once a week during the growing season. The $\mathrm{pH}$ of the growing medium was periodically monitored to maintain it at about 5.0.

At the end of the $54^{\text {th }}$ week, all seedlings visually judged to have maintained active growth throughout the experiment and that retained their shoot were harvested and partitioned into roots, main stem and branches. To extract the roots, the potting media containing the roots were enclosed in a fine wire mesh, tumbled to loosen contacts between roots and soil, then washed with tap water to remove the soil until only clean roots remained. Roots were then air-dried on greenhouse benches for 24 hours to remove surface water before being weighed to obtain green weight. All seedlings in the same experimental block were harvested and processed in the same day. Prior to oven drying, all seedling partitions were weighed on an electronic scale to obtain green weight. All plant parts were then ovendried to constant weight at $110^{\circ} \mathrm{C}$ for 72 hours. Dry weight of partitions was recorded and partitions were stored in a dry place for future reference. Seedling green and dry weight partitions and other traits covered in this article are described as follows:

GB - green weight for branches (stems and needles),

GS - green weight for main stem (stem and needles),

GR - green weight for roots,

TGW - total green weight $(\mathrm{GB}+\mathrm{GS}+\mathrm{GR})$,

DB - dry weight for branches (stems and needles),

DS - dry weight for main stem (stem and needles),

DR - dry weight for roots,

TDW - total dry weight (DB + DS + DR),

PGB - branch green weight as a fraction of total green weight (GB/TGW),

PGS - stem green weight as a fraction of total green weight (GS/TGW),

PGR - root green weight as a fraction of total green weight (GR/TGW),

PDB - branch dry weight as a fraction of total dry weight (DB/TDW),

PDS - stem dry weight as a fraction of total dry weight (DS/TDW),

PDR - root dry weight as a fraction of total dry weight (DR/TDW),

RSR - dry weight root to shoot ratio (DR/(DB+DS)),

SI - Stem Index (DS/(DB+DS)),

H36 - 36-week seedling height,

D36 - 36-week root collar diameter,

$\mathrm{BL}$ - 36-week branch length,

D54 - 54-week root collar diameter.

All weight and linear measurements are in gram (g) and millimetres $(\mathrm{mm})$, respectively.

In the present seedling data, the correlation for $\mathrm{DB}$, DS and DR with TDW was respectively, 0.96, 0.92 and 0.97 for individual seedlings. When dry weight of seedling partitions was expressed as fraction of the total seedling dry weight, the correlation for PDB, PDR and PDS with TDW was $0.33,0.39$ and 0.61 , respectively. This shows that weight ratios are not as dependent on seedling size as absolute weight and could provide better indication of variation in biomass allocation than analysis of absolute weight. It has long been observed that organ weights are related to total weight by the power function defined as $Y_{i}=a X_{i}^{b}$ where $Y_{i}$ is organ weight, $X_{i}$ is total weight, $a$ is an intercept and $b$ is the scaling or allometric parameter (GAYON, 2000; WHITE and Gould, 1965; Gould, 1971; Monserud and MARSHAL, 1999). The parameter $b$ calculated for family plots could be used in the analysis of covariance to adjust for allometric relationship between partition weight and total seedling weight (seedling size). In the present study, however, the parameter $b$ could not be calculated for family plots due to the single-tree plot design. Instead, analysis of weight ratios was considered sufficient for examination of biomass allocation. 


\section{Data Analysis}

Before the analysis, the data were examined and conformed to the normality and homogeneity of variance assumptions required for the analysis of variance. The following statistical model was fitted to all original and biomass-derived traits using the general linear models procedure (PROC GLM) in SAS (SAS INST. 2004).

$$
Y_{i j}=\mu+B_{i}+F_{j}+E_{i j}
$$

where $Y_{i j}=$ response for $j$ th family in ith block, $\mu=$ general mean, $B_{i}=$ effect due to $i t h$ block, $F_{j}=$ effect due to $j$ th family, $E_{i j}=$ residual for $j$ th family in ith block. Except for the mean, all effects were considered random, with the mean zero and the variances $\sigma_{b}^{2}$ (block), $\sigma_{f}^{2}$ (family) and $\sigma_{e}^{2}$ (residual). Individual-tree heritability $\left(h_{i}^{2}\right)$ and heritability for family means $\left(h_{f}^{2}\right)$ were calculated as follows:

$$
\begin{aligned}
& h_{i}^{2}=\frac{3 \times \sigma_{f}^{2}}{\sigma_{e}^{2}+\sigma_{f}^{2}} \\
& h_{f}^{2}=\frac{\sigma_{f}^{2}}{\left(\sigma_{e}^{2} / k\right)+\sigma_{f}^{2}}
\end{aligned}
$$

where, $k$ is average number of seedlings per family, and variance components are as previously defined. The use of 3 instead of 4 for the coefficient of relationship to calculate the additive genetic variance from the half-sib family variance $\left(\sigma_{f}^{2}\right)$ was meant to account for the family structure, because white spruce is self-fertile and inbred seedlings exhibit no inbreeding depression until later in life (FOWLER and PARK, 1983; PARK et al., 1984). Standard errors for $h_{i}^{2}$ and $h_{f}^{2}$ were calculated as described by BECKER (1975) and WRIGHT (1976), respectively. The additive genetic $\left(r_{a}\right)$, phenotypic $\left(r_{p}\right)$ and environmental $\left(r_{e}\right)$ correlation coefficients were calculated as follows:

$$
r_{x y}=\frac{\sigma_{x y}}{\sigma_{x} \times \sigma_{y}}
$$

where $r_{x y}$ is $r_{a}, r_{p}$ or $r_{e}$ correlation between trait $x$ and $y$; $\sigma_{x y}$ is the additive genetic, phenotypic or environmental covariance between trait $x$ and $y ; \sigma_{x}$ and $\sigma_{y}$ are respectively, square roots of the additive genetic, phenotypic or environmental variance components of trait $x$ and $y$. Variance and covariance components for calculation of heritability and correlation coefficients were obtained by equating the mean squares from PROC GLM to the expected mean squares and solving for the variance components.

The genetic correlations between seedling traits in the greenhouse and field height were calculated using the mean squares from the combined greenhouse-field analysis of variance as described by ROBERTSON (1959). To do this, data from the greenhouse and the field were converted to standard units by subtracting from each observation the general mean and dividing by the standard deviation. The following analysis of variance model was then fitted using PROC GLM treating the field and greenhouse experiments as two different experimental sites.

$$
Y_{i j n}=\mu+S_{i}+F_{j}+F S_{i j}+E_{i j n}
$$

where $Y_{i j n}=$ measurement on $n t h$ tree in $j t h$ family in ith site, $S_{i}=$ effect of the $i$ th site (field or greenhouse), $F S_{i j}=$ interaction of the $j t h$ family and $i t h$ site, $E_{i j n}=$ residual. The greenhouse-field genetic correlation was then calculated as:

$$
r_{a}=\frac{M S_{F}-M S_{F S}}{M S_{F}+M S_{F S}-2 \times M S_{E}}
$$

where, $r_{\alpha}=$ greenhouse-field additive genetic correlation, $\mathrm{MS}=$ mean squares, and subscripts $F, F S$, and $E$ stands for family, family $x$ site and residual, respectively.

Table 1. - Range of family means, percentages of variance components and heritability estimates.

\begin{tabular}{lcrllrlllll}
\hline Trait & Mean & \multicolumn{1}{c}{$\sigma_{b}^{2}$} & $\mathrm{~F}$ & $\mathrm{P}>\mathrm{F}$ & \multicolumn{1}{c}{$\sigma_{f}^{2}$} & $\mathrm{~F}$ & $\mathrm{P}>\mathrm{F}$ & $\sigma_{e}^{2}$ & $h_{i}^{2}$ & $h_{f}^{2}$ \\
\hline GB & $29.4(14.7-45.7)$ & 3.80 & 1.73 & 0.0131 & 10.66 & 2.07 & 0.0001 & 85.53 & $0.333 \pm 0.114$ & $0.516 \pm 0.115$ \\
GS & $18.4(11.4-29.4)$ & 5.51 & 2.01 & 0.0019 & 6.29 & 1.60 & 0.0052 & 88.20 & $0.200 \pm 0.100$ & $0.377 \pm 0.097$ \\
GR & $16.8(8.6-23.4)$ & 5.06 & 1.92 & 0.0037 & 7.55 & 1.72 & 0.0016 & 87.39 & $0.239 \pm 0.105$ & $0.419 \pm 0.103$ \\
TGW & $64.9(34.3-92.4)$ & 2.75 & 1.49 & 0.0531 & 9.01 & 1.84 & 0.0004 & 88.24 & $0.278 \pm 0.110$ & $0.458 \pm 0.108$ \\
PGB & $0.45(0.39-50.0)$ & 14.20 & 3.81 & 0.0001 & 5.91 & 1.61 & 0.0049 & 79.89 & $0.207 \pm 0.101$ & $0.379 \pm 0.099$ \\
PGS & $0.29(0.25-0.33)$ & 18.46 & 4.86 & 0.0001 & 6.18 & 1.68 & 0.0025 & 75.35 & $0.228 \pm 0.104$ & $0.404 \pm 0.102$ \\
PGR & $0.26(0.23-0.29)$ & 20.91 & 5.48 & 0.0001 & 5.34 & 1.60 & 0.0056 & 73.74 & $0.203 \pm 0.101$ & $0.374 \pm 0.098$ \\
DB & $17.6(10.1-26.4)$ & 1.99 & 1.38 & 0.0986 & 11.73 & 2.16 & 0.0001 & 86.28 & $0.359 \pm 0.117$ & $0.536 \pm 0.118$ \\
DS & $12.8(9.1-16.4)$ & 6.18 & 2.16 & 0.0007 & 7.79 & 1.76 & 0.0010 & 86.03 & $0.249 \pm 0.105$ & $0.433 \pm 0.104$ \\
DR & $14.2(8.2-19.7)$ & 3.39 & 1.61 & 0.0268 & 8.76 & 1.83 & 0.0005 & 87.85 & $0.272 \pm 0.109$ & $0.453 \pm 0.107$ \\
TDW & $44.8(27.0-61.6)$ & 1.80 & 1.32 & 0.1304 & 9.85 & 1.92 & 0.0002 & 88.34 & $0.301 \pm 0.113$ & $0.478 \pm 0.111$ \\
PDB & $0.39(0.35-0.43)$ & 11.89 & 3.31 & 0.0001 & 7.55 & 1.77 & 0.0009 & 80.56 & $0.257 \pm 0.108$ & $0.435 \pm 0.106$ \\
PDS & $0.29(0.26-0.33)$ & 16.27 & 4.32 & 0.0001 & 7.03 & 1.75 & 0.0011 & 76.70 & $0.252 \pm 0.107$ & $0.429 \pm 0.105$ \\
PDR & $0.31(0.29-0.34)$ & 9.53 & 2.77 & 0.0001 & 6.20 & 1.60 & 0.0053 & 84.27 & $0.206 \pm 0.102$ & $0.377 \pm 0.099$ \\
RSR & $0.46(0.41-0.52)$ & 9.19 & 2.69 & 0.0001 & 5.63 & 1.54 & 0.0098 & 85.19 & $0.186 \pm 0.099$ & $0.352 \pm 0.096$ \\
SI & $0.43(0.38-0.48)$ & 14.94 & 4.13 & 0.0001 & 8.07 & 1.88 & 0.0003 & 76.99 & $0.284 \pm 0.110$ & $0.469 \pm 0.109$ \\
\hline
\end{tabular}

B, GS and GR - green weight for branches, main stem and roots; TGW and TDW - total green and dry weight; PGB, PGS and PGR - green weight for branches, main stem and roots as fraction of total green weight; DB, DS, DR - dry weight for branches, main stem and roots; TDW - total dry weight; PDB, PDS and PDR - dry weight for branches, main stem and roots as fraction of total dry weight; RSR -r oot-to-shoot ratio; SI - stem index; $\sigma_{b}^{2} ; \sigma_{f}^{2}$ and $\sigma_{e}^{2}$-block, family and residual variance components; $h_{i}^{2}$ and $h_{f}^{2}$ individual-tree and family mean heritability. 


\section{Results and Discussion}

\section{Biomass Allocation}

Table 1 shows the overall mean and range of family means for PDB, PDS and PDR. Branches were the largest sinks of photosynthates, with $39.0 \%$ of the biomass allocated to them. In addition, $31.0 \%$ of the biomass was allocated to the roots, indicating that belowground growth constituted a substantial component of the plant even in the stable mineral- and moisturereach environment of the greenhouse. Furthermore, $29.0 \%$ of the biomass was allocated to the main stem. If this percentage of the main stem biomass were to be maintained to tree maturity, less than $30 \%$ of the biomass accumulated over the tree lifetime would be useful for timber production when taper is factored in. The mean RSR of $0.46(0.41-0.52)$ indicates that an approximate ratio of 1:2 existed between above and belowground biomass (Table 1). Although this does not indicated that the balance existed between the two seedling partitions, it shows that even in the resource-reach environment of the greenhouse a large root biomass is needed to support aboveground growth. The large root biomass is required to anchor the plant and absorb minerals and water needed for aboveground biological processes.

Overall, root dry weight (DR) was $80.7 \%$ of branch dry weight (DB). At the time of assessment, seedlings had poorly developed taproots. For such seedlings, we can expect much of the roots to contribute to absorption of water and minerals. On the contrary, for seedlings with well-developed branches as it were in this study, we may expect a limited branch biomass to contribute to transpiration and photosynthesis. Therefore, functionally, a near perfect balance may be expected in the present study between the branch partition exhibiting transpiration and photosynthesis and the root system absorbing moisture and minerals. Such a balance between the shoot and root systems is physiologically expected. In a stable environment that favours growth, a functional equilibrium exists between shoot and root growth. An increase in shoot growth often is accompanied by a proportional increase in root growth and vice versa (CANNELL, 1985). When resources are limited, plants allocate resources preferentially between roots and shoots. A limitation in light for photosynthesis prompts the plant to allocate more resources to shoot growth, whereas limitations in moisture and nutrients divert more resources to root growth (PoORTER and NAGEL, 2000). This preferential growth of plant organs in response to resource limitations increases the ability of the plant to extract more of the limited resources (SMITH, 1996). More importantly, organ-specific preferential growth enables the plant to maintain the functional balance between the shoot and roots by periodically adjusting the size of one compartment relative to the other.

\section{Genetic Variation and Heritability}

Table 1 shows percentages of variance components, the F-test and heritability estimates for measured and derived traits. Genetic variation and heritability were slightly higher when calculated from dry weight than green weight. Main stem weight had the lowest heritability, especially when calculated from green weight (GS). There were high similarities in the percentages of the family variance $\left(\sigma_{f}^{2}\right)$ for green weight allocation where the variances were $5.91 \%$ (PGB), 6.18\% (PGS) and $5.34 \%$ (PGR). The corresponding values for dry weight allocation were $7.55 \%$ (PDB), $7.03 \%$ (PDS), and $6.20 \%(\mathrm{PDR})$, which also shows that genetic variation in biomass allocation is better detected using dry weight than green weight.

The heritability values of biomass production and allocation were generally moderate $\left(h_{i}^{2}<0.36\right.$ and $\left.h_{f}^{2}<0.54\right)$. Considering the size of the standard errors, variation in biomass production and its allocation to shoot and root components were under low genetic control. Similar low heritability values for biomass production were observed in lodgepole pine (Pinus contorta Dougl.) (WU and YEH, 1997), white spruce (KHALIL, 1985), Scotch pine (Pinus sylvestris L.) (VELLING and Tigerstedt, 1984), trembling aspen (Populus tremuloides Michx.) (LeHN and Higginbotham, 1982), and Norway spruce (Picea abies (L.) Karst.) (Sonesson et al., 2002; MARI et al., 2003; SONESSON and ERIKSSON, 2003). In Scotch pine, SonESSON and ERIKSSON (2000) found moderate to high $h_{i}^{2}$ for shoot and root dry weight for populations from central Sweden but low heritabilities for populations from southern Sweden. High heritabilities for shoot and root dry weight were found in mountain hemlock (Tsuga mertensiana Bong.) (BENOwICZ and EL-KASSABY, 1999), and Eucalyptus grandis W. Hill ex Maid. and Eucalyptus globulus Labill. (MARCAR et al., 2002).

These studies also showed that heritabilities for biomass production tended to vary considerably under different experimental conditions. For example, in Norway spruce, SONESSON et al. (2002) showed that $h_{i}^{2}$ were higher at high temperature and high moisture than at low temperature and low moisture. A combination of high moisture and low temperature yielded higher $h_{i}^{2}$ than a combination of high temperature and low moisture. In contrast, SONESSON and ERIKSSON (2003) found that for Norway spruce, heritabilities were higher in drought stressed trees than well-watered ones. SuRLEs et al. (1995), on the other hand, found that for Pinus elliottii Engelm. $h_{f}^{2}$ was very high at both low and high nitrogen treatments. In $E$. grandis and $E$. globulus, heritability values differed greatly between salt and moisture treatments (MARCAR et al., 2002). For the present study, heritabilities were estimated at the light, nutrient and watering regime used to raise white spruce seedlings for operational reforestation in Alberta. Therefore, they are considered reliable for practical selection in a tree improvement context in Alberta.

The RSR was the least genetically variable of all traits analysed in this study. The family variance for RSR was $5.63 \%$ of the total variance (Table 1). The low genetic variance and heritability for RSR observed in the present study is consistent with what has been observed in other conifers (WU and YEH, 1997; SONESSON and ERIKSSON, 2000; MARI et al., 2003; SONESSON et al., 2002). The functional balance between shoot and root systems (see Cannell, 1985; Poorter and Nagel, 2000) implies that 
RSR should vary little among genotypes, resulting to low heritability.

The high RSR is considered essential in drought tolerance, because it indicates a high moisture extraction capacity of the roots relative to the transpiring shoots. Therefore, selection and breeding for high RSR could improve drought tolerance. However, low heritability for RSR implies that selection may not be an effective way of changing RSR. The natural functional balance between shoot and root biomass also implies that artificial and natural selection cannot significantly alter RSR as long as the shoot and root systems are interdependent. Even if selection for RSR were effective, breeding to increase the root biomass while restricting shoot growth would not be attempted for a plantation whose end product is wood. Therefore, instead of breeding, silvicultural methods such as root pruning to promote lateral root growth, regulation of nitrogen $(\mathrm{N})$, phosphorus $(\mathrm{P})$, potassium $(\mathrm{K})$ and other mineral nutrients to promote root development while limiting shoot growth (MARSCHNER et al., 1996; MCDONALD et al., 1996; GLIMSKAR and ERICSSON, 1999) could be used. These methods could alter the relative size of the root and shoot systems at a critical field establishment time, allowing seedlings to acquire enough moisture and nutrients with limited transpiration. Such alteration of seedling architecture is temporal and non-genetic, designed only to facilitate seedling survival in low moisture environments until a well-functioning root system is established.

In this study, SI expressed as a ratio of DS to the total aboveground dry weight was approximately 0.43 (Table 1). This conversion ratio suggests that on average, $43 \%$ of the shoot biomass was allocated to a potentially harvestable part of the tree. Elsewhere (see BENOwICZ and El-Kassaby, 1999; Velling and Tigerstedt, 1984; Wu and YEH, 1997), this ratio has been called the harvest index (HI), a term not used in this article because SI in forest trees does not have the same meaning as $\mathrm{HI}$ in agricultural crops. In this study, heritability for SI was relatively higher than most of the traits examined (Table 1) and similar to that observed in lodgepole pine by WU and YEH (1997). The present heritability for SI was lower than that reported by VELLING and TIGERSTEDT (1984) in Scotch pine. BENOWICZ and EL-KASSABY (1999) reported a much higher heritability $(0.92 \pm 0.36)$ for this trait in mountain hemlock, which suggests that selection for SI could result in large genetic gains.
There are, however, biological and practical limitations in the breeding for high SI in forest trees. In grain crops, $\mathrm{HI}$ is the ratio of grain with aboveground (grain + straw) biomass. Therefore, HI measures the reproductive against vegetative growth potential, which are two distinct processes occurring at different times in the life cycle of an annual plant. In trees, growth in the main stem and branches are part of the same process of shoot growth and occur simultaneously. These two parts of the tree are also interdependent given high genetic $\left(r_{a} \approx 0.95\right)$, phenotypic $\left(r_{p} \approx 0.86\right)$ and environmental $\left(r_{e} \approx 0.86\right)$ correlation between DS and DB (Table 2). Thus, because the tree trunk is a sink for photosynthates from the branches, DS will increase in proportional to the increase in DB and TDW. Genetic improvement for $\mathrm{HI}$ in grain crops has been achieved through development of dwarf high yielding cultivars (POEHLMAN and SLEPER, 1995), because the desired product is grain and not straw, and grain production in cereal crops is dependent on the two uppermost leaves. This cannot be achieved in forest trees where the harvestable product is part of the vegetative biomass.

Instead of direct selection, SI could be indirectly improved by breeding for self-pruning. This study showed that on average $58 \%$ of shoot biomass was allocated to branches. Due to self-shading, leaves on older branches contribute little to photosynthesis. Such leaves, become sinks for photosynthates from young branches and waste energy through respiration. Breeding for self-pruning could eliminate such sinks, allowing more photosynthates to be allocated to the main stem to increase SI. Breeding for self-pruning is essentially breeding for optimum leaf area index (LAI), allowing leaves to contribute fully to photosynthesis while wasting less energy to respiration.

\section{Correlation Coefficients}

Table 2 shows that correlations among seedling partitions were $0.94-0.96\left(r_{a}\right), 0.81-0.91\left(r_{p}\right)$ and $0.83-0.91$ $\left(r_{e}\right)$. Likewise, the genetic correlation between green and dry weight for the same traits was approximately 1.0, while the other correlations ranged from 0.98 to $0.99\left(r_{p}\right)$ and 0.98 to $1.0\left(r_{e}\right)$. Thus, the use of green weight may not change the order families are ranked for dry weight. The perfect correlation between green and dry weight for the same traits could be useful in selection to improve biomass production and allocation in trees. Although heritabilities were lower for green weight than

Table 2. - Correlation coefficients between biomass traits and biomass with primary seedling traits.

\begin{tabular}{lclllrrr}
\hline & & & & \multicolumn{3}{c}{ Pearson's Correlation Coefficient } \\
\cline { 3 - 7 } Trait Pair & $r_{a}$ & $r_{p}$ & $r_{e}$ & Biomass Trait & H36 & D54 \\
\hline GB \& GS & $0.943 \pm 0.014$ & 0.808 & 0.826 & GB & 0.65 & 0.66 \\
DB \& DS & $0.947 \pm 0.013$ & 0.860 & 0.864 & DB & 0.67 & 0.67 & 0.77 \\
DB \& DR & $0.949 \pm 0.012$ & 0.910 & 0.913 & GS & 0.62 & 0.72 & 0.75 \\
DS \& DR & $0.955 \pm 0.011$ & 0.879 & 0.883 & DS & 0.61 & 0.58 & 0.67 \\
GB \& DB & $0.999 \pm 0.000$ & 0.987 & 1.002 & DR & 0.66 & 0.70 & 0.73 \\
GS \& DS & $1.015 \pm 0.004$ & 0.976 & 0.978 & TGW & 0.79 & 0.67 & 0.68 \\
TGW \& TDW & $1.001 \pm 0.000$ & 0.991 & 0.992 & TDW & 0.78 \\
\hline
\end{tabular}

$r_{a}, r_{p}, r_{e}$-genetic, phenotypic and environmental correlation, respectively; GB and GS - green branches and main stem, respectively; DB, DS and DR - dry branches, main stem and roots; TGW and TDW - total green and dry weight, respectively; H36 - 36-week seedling height; D54 - 54-week root collar diameter; BL - 36-week branch mean branch length; All Person's correlations for family means are significant $(P \leq 0.0001)$. 
dry weight (Table 1), the perfect genetic correlations between the two shows that selection based on green or dry weight could produce the same realised gain, because the same families could be selected. Processing and oven drying of plant parts is tedious, especially for large trees. This could limit the sample size and reduce accuracy in the estimation of genetic parameters and subsequently, prediction of genetic gains. Therefore, assessing variation in green weight is the only viable alternative to dry weight if adequate genetic correlation between the two can be established.

The correlation between seedling partition dry weight and seedling primary traits such as height, root collar diameter and branch size could be used to simplify collection of biomass data. Instead of harvesting and drying all seedlings, dry weight could be obtained only for a random sample of seedlings per family. Allometric equations could then be developed between these dry weight and seedlings primary traits. Using these allometric equations, dry weight for the remaining seedlings could be estimated from their primary traits as predictor variables, thus allowing for acquisition of a sufficient sample size for genetic analysis.

\section{Greenhouse-Field Correlation}

Table 3 shows that the genetic correlations between greenhouse biomass traits and field height were low and negative. Considering the standard errors, these correlations are not far from zero. The corresponding Pearson's correlations for family means were also very low and negative (Table 3). Therefore, indirect early selection for field height using dry weight production in the greenhouse may not be effective. Similar low negative genetic correlation between seedling biomass traits and field height were found in loblolly pine (Pinus taeda L.) by Li et al. (1991) and Norway spruce (SONESSON et al., 2002). In Scotch pine, Jonsson et al. (2000) found that genetic correlations between seedling biomass and field height were lower at dense than at wide spacing. Dry weight is a composite variable of height, diameter and wood density, which is a function of wood structure and chemistry. Therefore, the lack of correlation between greenhouse biomass and a single primary field trait such as height is not surprising.

\section{Conclusion}

Genetic analysis of height and diameter has provided useful information for selection and breeding for volume production. However, studies of these simple traits do not allow us to examine the overall variation in tree growth, because growth is a multidimensional variable. Analysing dry weight and its partitioning to the different tree compartments can do this. From the present analysis of green and dry weight, we have concluded the following, (1) biomass production and allocation to roots, main stem and branches exhibited low to moderate heritability considering the young age of the seedlings. This is in contrast to high heritabilities for height (RWEYONGEZA et al., 2004), root collar diameter and branch length (RWEYONGEZA, 2002) for the same experiments. Because growth of tree organs is proportional to the size of the tree and individual organs exhibit allometric relationships with each other, variation in biomass allocation tends to be more environmentally rather than genetically determined, (2) root dry weight was highly correlated genetically, phenotypically and environmentally with shoot dry weight traits. This confirms that a functional equilibrium existed between shoot and root growth. Hence, selection for high RSR may not be an effective way to improve drought tolerance in white spruce from Alberta. Instead, silvicultural manipulation of the nursery stock could be more effective in improving RSR than tree breeding, (3) when analysed as a fraction of the total seedling weight, biomass allocation, especially for the branch and root partitions, exhibited lower heritability than when analysed on absolute measurements. This confirms that analysis of absolute weight to represent biomass allocation fails to recognise the allometric dependence of partition weight to total seedling size (weight), thus leading to overestimation of heritability, (4) heritability for biomass production was underestimated when calculated using green weight as opposed to dry weight. However, the genetic correlation between green and dry weight was near perfect, suggesting that the use of green weight in place of dry weight would lead to selection of the same families. Therefore, it is safe to use genetic parameters from green weight for selection to improve dry weight, (5) the relationship between biomass and primary tree traits

Table 3. - Genetic correlation between seedling dry weights in the greenhouse and field height growth.

\begin{tabular}{|c|c|c|c|}
\hline \multirow[t]{2}{*}{ Trait Pair } & \multicolumn{2}{|l|}{ Chinchaga } & Saddle Hills \\
\hline & $r_{a}$ & $r_{\bar{f}}$ & $r_{a}$ \\
\hline$\overline{\mathrm{DB} \& \mathrm{H} 10}$ & $-0.124 \pm 0.248$ & -0.114 & $-0.214 \pm 0.315-0.144$ \\
\hline DB \& H11 & $-0.219 \pm 0.240$ & -0.156 & $-0.258 \pm 0.352-0.137$ \\
\hline DS \& H10 & $-0.309 \pm 0.272$ & -0.200 & $-0.291 \pm 0.360-0.216$ \\
\hline DS \& H11 & $-0.403 \pm 0.252$ & -0.227 & $-0.385 \pm 0.382-0.208$ \\
\hline DR \& H10 & $-0.211 \pm 0.259$ & -0.182 & $-0.222 \pm 0.338-0.202$ \\
\hline DR \& H11 & $-0.290 \pm 0.248$ & -0.210 & $-0.246 \pm 0.381-0.188$ \\
\hline TDW \& H10 & $-0.178 \pm 0.255$ & -0.160 & $-0.241 \pm 0.324-0.185$ \\
\hline TDW \& H11 & $-0.274 \pm 0.243$ & -0.195 & $-0.297 \pm 0.358-0.175$ \\
\hline
\end{tabular}

$r_{a}$-genetic correlation; $r_{\bar{f}}$-Pearson's correlation for family means; $\mathrm{H} 10$ and H11 - field height at 10 and 11 years; DB, DS, DR and TDW - dry weight for branches, main stem, roots and whole seedling. All $r_{\bar{f}}$ are not significant $(P>0.05)$. 
such as height and diameter provides the opportunity to simplify the collection of dry weight data in large experiments. Instead of harvesting and weighing all trees, a representative destructive sample of trees could be used to develop partition-specific allometric equations and use them to estimate dry weight of the remaining trees with height or diameter as predictor variables, (6) there was poor genetic correlation for greenhouse biomass production with 10- and 11-year height at two field sites for the same families. If family ranking persist on these field sites, seedling biomass production in indoor trials may not be useful in identifying families that would be superior in height growth at the rotation age.

\section{Acknowledgements}

We acknowledge the technical assistance provided by the staff at the Alberta Tree Improvement and Seed Centre (ATISC), and the greenhouse staff in the Department of Agricultural, Food and Nutritional Science at the University of Alberta, and ATISC for use of their field data. We also thank the two anonymous reviewers for providing critical comments and suggestions to the original manuscript. Manning Diversified Forest Products provided funding for this research to FCY.

\section{References}

Adams, W. T., S. N. Aitken, D. G. Joyce, G. T. Howe and J. V. HERNANDEZ (2001): Evaluating efficacy of early testing for stem growth in Douglas-fir. Silvae Genet. 50: 167-175.

AvERY, T. E. and H. E. BURKHART (1994): Forest Measurements. $4^{\text {th }}$ Ed. McGraw-Hill Inc, New York.

BECKER, W. A. (1975): Manual of Quantitative Genetics. Washington State University Press, Pullman.

Benowicz, A. and Y. A. El-Kassaby (1999): Genetic variation in mountain hemlock (Tsuga mertensiana Bong.): quantitative and adaptive attributes. For. Ecol. Manage. 123: 205-215.

Cannell, M. G. R. (1985): Dry matter partitioning in tree crops. pp. 160-193. In: Attributes of trees as crop plants, edited by M. G. R. CANNELL and J. E. JACKSON, Institute of Terrestrial Ecology, Penicuik, Scotland.

Fowler, D. P. and Y. S. PARK (1983): Population studies of white spruce. I. Effects of self-pollination. Can. J. For. Res. 13: 1133-1138.

GAYON, J. (2000): History of the concept of allometry. American Zoologist 40: 748-758.

GLIMSKAR, A. and T. ERICSSON (1999): Relative nitrogen limitation at steady-state nutrition as a determinant of plasticity in five grassland plant species. Ann. Bot. 84: 413-420.

Gould, S. J. (1971): Geometric similarity in allometric growth: A contribution to the problem of scaling in the evolution of size. American Naturalist 105: 113-136.

HODGE, G. R. and T. L. White (1992): Genetic parameter estimates for growth traits at different ages in slash pine and some implications for breeding. Silvae Genet. 41: 252-262.

Jonsson, A., G. ERIKsson, Z. Ye and F. C. YeH (2000): A retrospective early test of Pinus sylvestris seedlings grown at wide and dense spacing. Can. J. For. Res. 30: 1443-1452.

KHALIL, M. A. K. (1985): Heritability of juvenile characters of white spruce (Picea glauca (Moench) Voss) in central Newfoundland, Canada. Theor. Appl. Genet. 69: 247-251.

KREMER, A. (1992): Prediction of age-age correlation of total height based on serial correlations between height increments in maritime pine (Pinus pinaster Ait.). Theor. Appl. Genet. 85: 152-158.

LEHN, G. A. and K. O. HigGinBothAM (1982): Natural variation in merchantable stem biomass and volume among clones of Populus tremuloides Michx. Can. J. For. Res. 12: 83-89.

Li, B., S. E. McKeand and H. L. Allen (1991): Seedling shoot growth of loblolly pine families under two nitrogen levels as related to 12-year height. Can. J. For. Res. 21: 842-847.

Marcar, N. E., D. F. Crawford, A. Saunders, A. C. MATHESON and R. A. ARNOLD (2002): Genetic variation among and within provenances and families of Eucalytpus grandis W. Hill and E. globulus Labill. subsp. globulus seedlings in response to salinity and water lodging. For. Ecol. Manage. 162: 231-249.

MARI, S., G. JANSSON and A. Jonsson (2003): Genetic variation in nutrient utilization and growth traits in Picea abies seedlings. Scand. J. For. Res. 18: 19-28.

MARSCHNER, H., E. KIRKBY and I. CAKMAK (1996): Effect of mineral nutritional status on shoot-root partitioning of photoassimilates and cycling of mineral nutrients. J. Exper. Bot. 47: 1255-1263.

MCDonald, A., T. ERICsson and C. LARSSON (1996): Plant nutrition, dry matter gain and partitioning at the whole-plant level. J. Exper. Bot. 47: 1245-1253.

Monserud, R. A. and J. D. Marshall (1999): Allometric crown relations in three Idaho conifer species. Can. J. For. Res. 29: 521-535.

PARK, Y. S., D. P. Fowler and J. F. Coles (1984): Population studies of white spruce. II. Natural inbreeding and relatedness among neighbouring trees. Can. J. For. Res. 14: 909-913.

Poehlman, J. M. and D. A. Sleper (1995): Breeding field crops. $4^{\text {th }}$ Ed. Iowa State University Press. Ames.

Poorter, H. and O. NAGEL (2000): The role of biomass allocation in the growth response of plants to different levels of light, $\mathrm{CO}_{2}$, nutrients and water: a quantitative review. Aust. J. Plant. Physiol. 27: 595-607.

ROBERTSON, A. (1959): The sampling variance of the genetic correlation coefficient. Biometrics 15: 469-485.

RWEYONGEZA, D. M. (2002): Genetic analysis of seasonal seedling height growth curves and early selection in white spruce. Ph.D. thesis. University of Alberta. Edmonton.

RweyongezA, D. M., F. C. YeH and N. K. DhIR (2004): Genetic parameters for seasonal height and height growth curves of white spruce seedlings and their implications to early selection. For. Ecol. Manage. 187: 159-172.

SAS INSTITUTE (2004): SAS system for windows. Version 9.1. Carry, NC.

Smith, R. L. (1996): Ecology and field biology. $5^{\text {th }}$ Ed. Harper Collins College Publishers, New York.

Sonesson, J. and G. ERIKsson (2000): Genotypic stability and genetic parameters for growth and biomass traits in a water $x$ temperature factorial experiment with Pinus sylvestris L. seedlings. For. Sci. 46: 487-495.

SONESSON, J. and G. ERIKSSON (2003): Genetic variation in drought tolerance in Picea abies seedlings and its relationship to growth in controlled and field environments. Scand. J. For. Res. 18: 7-18. 
Sonesson, J., G. JANSSON and G. ERIKSson (2002): Retrospective genetic testing of Picea abies under controlled temperature and moisture regimes. Can. J. For. Res. 32: 81-91.

Surles, S. E., T. L. White and G. R. Hodge (1995): Genetic parameter estimates for seedling dry weight traits and their relationship with parental breeding values in slash pine. For. Sc. 41: 546-563.

ST. ClaIR, J. B. (1994a): Genetic variation in tree structure and its relation to size in Douglas-fir. I. Biomass partitioning, foliage efficiency, stem form, and wood density. Can. J. For. Res. 24: 1226-1235.

ST. ClaIR, J. B. (1994b): Genetic variation in tree structure and its relation to size in Douglas-fir. II. Crown form, branch characters, and foliage characters. Can. J. For. Res. 24: 1236-1247.

Velling, P. and M. A. Tigerstedt (1984): Harvest index in a progeny test of Scots pine with preference to the mode of selection. Silva Fennica. 18: 21-32.
White, J. F. and S. J. Gould (1965): Interpretation of the coefficient in the allometric equation. American Naturalist 99: $5-18$.

WRIGHT, J. W. (1976): Introduction to Forest Genetics. Academic Press, New York.

WU, H. X. and F. C. YEH (1997): Genetic effect on biomass partition and tree architecture in seedlings of Pinus contorta subsp. latifolia in Alberta, Canada. For. Genet. 4: $123-130$.

Wu, H. X., F. C. Yeh, R. P. Pharis, B. P. Dancik, I. B. JiANG, I. DyMock and N. K. DHIR (1995): Genetic parameters of greenhouse growth and performance of 2-year Pinus contorta subsp. latifolia. Scand. J. For. Res. 10: 12-21.

YANCHUK, A. D. and G. K. KISS (1993): Genetic variation in growth and wood specific gravity and its utility in the improvement of interior spruce in British Columbia. Silvae Genet. 42: 141-148.

\title{
Genetic Variation of Korean Pine (Pinus koraiensis Sieb. et Zucc.) at Allozyme and RAPD Markers in Korea, China and Russia
}

\author{
By Z. S. KIM ${ }^{1), 6)}$, J. W. HwANG ${ }^{2)}$, S. W. LEE $^{3)}$, C. YANG ${ }^{4)}$ and P. G. GorovoY ${ }^{5)}$
}

(Received $5^{\text {th }}$ August 2005)

\begin{abstract}
We studied and compared genetic variation of Korean pine (Pinus koraiensis Sieb. et Zucc.) from 12 natural populations in Korea, China, and Russian Far East using allozymes and random amplified polymorphic DNAs (RAPDs). Eighteen polymorphic allozyme loci and 38 polymorphic RAPD fragments were analyzed. The level of allozyme diversity $\left(A=1.95, P_{95}=46.8 \%, H_{0}=\right.$ $\left.0.158, H_{\mathrm{e}}=0.169\right)$ and the degree of genetic differentiation $\left(F_{\mathrm{ST}}^{\mathrm{e}}=0.069\right)$ were comparable to those of other pines with similar life histories and ecological traits. Allozyme $\left(H_{\mathrm{e}}\right)$ as well as RAPD (Shannon's index) variation decreased from south (Korea) to north (Russia), providing an evidence for the hypothesis of Korean pine's northward migration. Differentiations among three different regions (Korea, China, and Russia) as well as among populations within regions were small. Substantial gene flow $\left(N_{m}=3.4\right)$ may be a partial explanation to

1) Division of Biotechnology and Genetic Engineering, College of Life and Environmental Sciences, Korea University, Seoul 136701, Korea.

2) Department of Forest Resources, College of Natural Resources, Yeung Nam University, Gyeongsangbuk-do 712-749, Korea.

${ }^{3}$ ) Korea Forest Research Institute, Seoul 130-712, Korea.

4) Northeast Forestry University, Harbin 150040, China.

5) Pacific Institute of Bioorganic Chemistry, Far Eastern Branch, Russian Academy of Sciences, Vladivostok 690950, Russia.

6) To whom correspondence should be addressed: Tel. 82-2-32903011, Fax 82-2-922-1724, E-mail: zskim@korea.ac.kr
\end{abstract}

this result. Clustering algorithms using various genetic distance measures showed some decisive geographic patterns at allozyme and RAPD level: the geographically close populations tended to be clustered together. On the other hand, two Chinese populations, Xobukho and Wangging, were grouped with the Russian populations rather than with the other Chinese populations. The Xiaoxing'anling and other mountains extended from north to south seemed to function as a barrier against gene flow between the Xobukho and Wangging (located east of the mountains) and the other Chinese $P$. koraiensis populations (located west of the mountains). The genetic diversities and differentiation estimated from RAPD data in Korean pine were congruent with those of allozymes.

Key words: Pinus koraiensis, allozymes, RAPDs, genetic variation, Korea, China, Russian Far East.

\section{Introduction}

The five stone pine species occur only in the Northern Hemisphere - one species in North America (Pinus albicaulis) and the other four in Eurasia and East Asia (Pinus cembra, Pinus sibirica, Pinus pumila and Pinus koraiensis). Taxonomically they fall under subsection Cembrae in section Strobus. They are characterized by having five needles in a fascicle, cones that do not open at maturity, and wingless seeds. CRITCHFIELD and LITTLE's (1966) maps show that the distribution of five 